\title{
Editorial
}

\section{Acta Dermatovenerologica Alpina, Pannonica et Adriatica: 2019 publishing statistics}

\author{
Tjaša Teržan ${ }^{1}$, Anja Šterbenc ${ }^{1}$, Mario Poljak ${ }^{2}{ }^{\otimes}$, Jovan Miljković 3 \\ ${ }^{1}$ Acta Dermatovenerologica Alpina, Pannonica et Adriatica, Technical Editor. ${ }^{2}$ Acta Dermatovenerologica Alpina, Pannonica et Adriatica, Editor. ${ }^{3}$ Acta \\ Dermatovenerologica Alpina, Pannonica et Adriatica, Editor-in-Chief.
}

For an editorial office, insight into a journal's publishing statistics is of great importance for improving the journal's performance. Moreover, in order to secure timely publication of their work, authors can consider the timeline of the editorial process of a given journal when identifying potential journals for publication. Time to publication and rejection rates can be especially important deciding factors for authors.

In February 2020, we collected data to evaluate the publishing statistics of Acta Dermatovenerologica Alpina, Pannonica et Adriatica (ADAPA) for the previous year. Data for manuscripts submitted between January 1st, 2019 and December 31st, 2019 were extracted from a journal database. The following variables were evaluated: article types received, duration of editorial process from the first submission to the first and final decision, types of decisions, and total number of weeks to online publication.

Thus, a total of 70 manuscripts were submitted to ADAPA in 2019, including 39 (56\%) original articles, 21 (30\%) case reports, eight $(11 \%)$ reviews, and two $(3 \%)$ commentaries. For two original articles and one case report, the editors suggested the original manuscript be modified into a short report. The largest number of manuscripts were submitted to ADAPA during August, May, and July (Fig. 1).

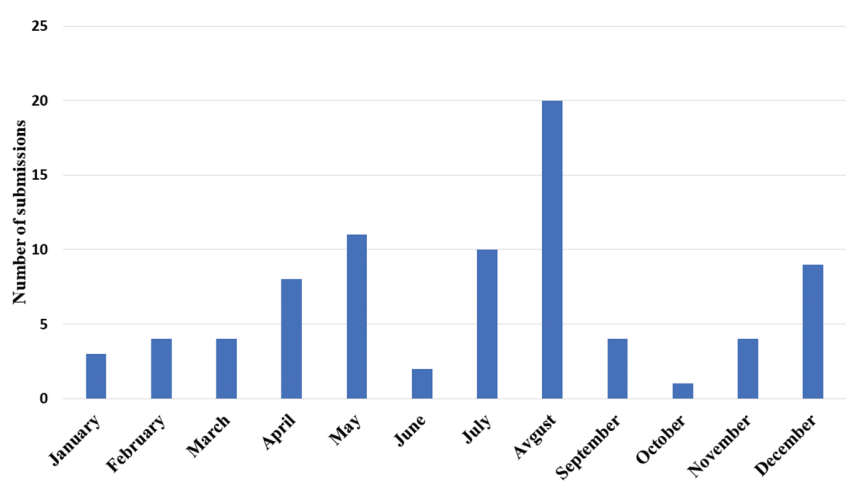

Figure 1 | Number of submissions to Acta Dermatovenerologica Alpina, Pannonica et Adriatica by month for 2019.

Each manuscript submitted is first examined by a commercial plagiarism detection program. The average similarity index for manuscripts submitted last year was 17\% (range o-53\%). Of all manuscripts submitted, $37 / 70$ (53\%) had a similarity index above $15 \%$, in which case the editors encouraged the authors to reduce the similarities in order to proceed with the editorial process.

Following the plagiarism check, manuscripts are internally reviewed by the editors and subsequently submitted for peer review if deemed original and interesting. In total, 8/70 (12\%) manuscripts were rejected immediately by the editors due to lack of originality, a high similarity index and/or duplicate publication, lack of feedback from the authors, incomplete submissions (e.g., missing submission forms), and out-of-scope submissions.

Of the articles that were subjected to peer review, 17 (26\%) were rejected based on unfavorable peer reviews, 18 (28\%) needed major revision, and 20 (31\%) minor revision. Overall ADAPA's acceptance and rejection rates for 2019 were $54 \%$ and $46 \%$, respectively. Rejected submissions also included three (11\%) manuscripts for which the authors did not submit the revised manuscript by the deadline despite several warnings.

The median overall time from submission to first decision (revise/reject), final decision, and publication are shown in Table 1. Of the 55 manuscripts reviewed, 10 (18\%) needed a second revision. The median time from submission to final decision (accept/ reject) for all submissions was 63.5 (range 11-311) days. The median overall time from first submission to print publication was 159 (range 58-332) days and did not differ significantly among the four issues in 2019.

Table 1 | Time to first and final decision and publication in Acta Dermatovenerologica Alpina, Pannonica et Adriatica for 2019.

\begin{tabular}{lc}
\hline Time & Median (range) \\
\hline To first decision, days & $59(5-271)$ \\
To final decision, days & $63.5(11-311)$ \\
From submission to publication, days & $159(58-332)$ \\
\hline
\end{tabular}

Our analysis has shown that the main type of manuscripts submitted to ADAPA are original research articles (56\%).

Due to our zero tolerance for plagiarism, we have set the upper limit for similarity with previously published literature at $15 \%$, which means that approximately every second submission to ADAPA needs initial revision before it can be sent for peer review. Whereas only one attempted case of duplicate publication was identified for manuscripts submitted in 2019, we have a long history of dealing with such hurdles, including two recent cases of duplicate publication that resulted in retractions $(1,2)$, one of them was publicly praised by Retraction Watch, a webpage dedicated to tracking retractions in scientific communities (3).

As shown in Figure 2, the majority ( $85 \%$ ) of submissions undergo rigorous peer review, resulting in an overall acceptance rate of $54 \%$. Despite the fact that our journal has not yet been awarded an official impact factor, an overall rejection rate of $46 \%$ suggests that the quality of ADAPA is ensured.

One factor that could be improved is the time to first decision and publication. Whereas a peak in the number of manuscripts submitted during July and August could potentially prolong the time to publication due to a larger number of accepted manuscripts in the following months and an upper limit of articles per issue, we have not noticed significant differences in time to publication with respect to the month of initial submission. Nevertheless, we aim to ensure timely publication of the most influential research, 
which may consequently prolong publication times for other manuscripts. In addition, we aim to balance the proportion of original/review articles and case reports per issue and, if possible, avoid publishing more than one manuscript from the same research group in any given issue of the journal; these measures can artificially prolong publishing statistics. Generally, original articles tend to have slightly longer times to publication, mostly due to the longer peer review time (and sometimes need for second revision). Suitable peer reviewers may be difficult to find, especially because all our reviewers do their work on a volunteer basis. Whereas peer review may be time-consuming, the experience can also prove to be rewarding. Hence, in order to ensure timely publication of the most important research in ADAPA, the editorial office would like to invite all professionals willing to participate in the peer review process.

\section{References}

1. Retraction note: Inflamed bilateral linear atrophoderma of Moulin in an adult woman: a case report. Acta Dermatovenerol Alp Pannonica Adriat. 2019;28:49.

2. Retraction: The measurement of serum tumor necrosis factor-alpha levels in patients with lichen planus. Indian J Dermatol. 2019;64:165.

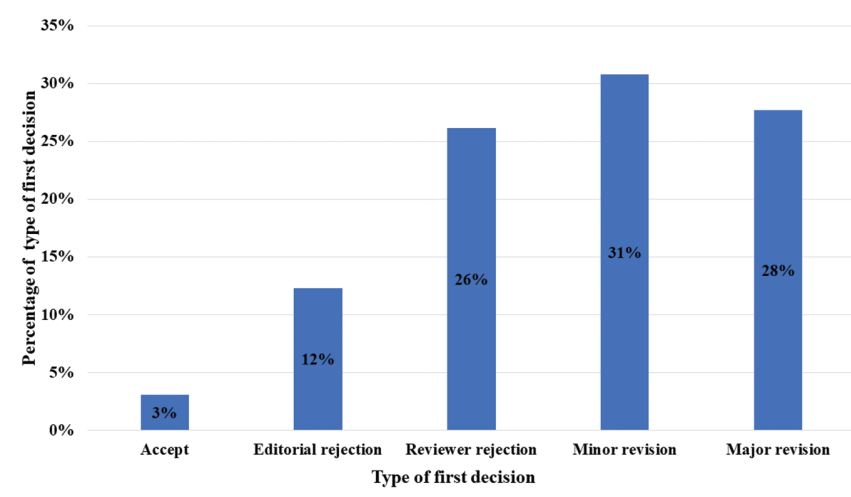

Figure 2 | Percentage and types of first decisions for manuscripts received.

3. Retraction Watch [Internet]. [cited 2020 Feb 24]. Available from: https://retrac tionwatch.com/2019/04/16/too-much-skin-in-the-game-derm-journal-callsout-author-for-duplication/. 